\title{
Operational Properties of Nanocomposites based on Polycaproamide and Modified Montmorillonite
}

\author{
Volodymyr Krasinskyi ${ }^{1, *}$, Oleg Suberlyak ${ }^{2}$, Yurii Klym ${ }^{2}$ \\ 1,* Lviv Polytechnic National University, Department of Chemical Technology of Plastics, 12, Bandera Str., Lviv, 79013, Ukraine \\ ${ }^{2}$ Lviv Polytechnic National University, Department of Chemical Technology of Plastics, 12, Bandera Str., Lviv, 79013, Ukraine
}

\begin{abstract}
A new method of layered silicate (montmorillonite) intercalation by polyvinylpyrrolidone in the solution under ultrasonic treatment is described in this work. The effect of intercalated montmorillonite on physico-mechanical, thermophysical and insulating properties of polycaproamide PA- 6 has been determined.
\end{abstract}

Keywords: nanocomposite; physico-mechanical properties; polycaproamide PA-6; montmorillonite; polyvinylpyrrolidone; thermophysical properties.

\section{Introduction}

One of the most promising new directions in the science of composite materials in recent years is creating polymer composites with nanofillers. These materials has high dispersibility of nanoparticles filler that provide complex with improved properties wich can not be achieve in traditional microcomposites in consequence.

Today in the field of development of layered silicate polymeric nanocomposites the main attention is focused on the achievement of high level of nanoparticles exfoliation in the polymeric matrix that specifies high operational characteristics. Thus the choice of effective organic modifiers of layered silicate is an urgent problem because the modifier ensures high adhesion of the filler with polymeric matrix. From this point of view the study of effect of organic clay on the structure and properties of obtained nanocomposites with unknown nature is of great interest. The determination of mentioned regularities will give the possibility to control the structure and predict the properties of the composites based on organic clay [1, 2].

One of the approaches used to improve thermodynamic compatibility of nonpolar polymer with layered silicates is the introduction of polymeric polar modifier [3].

The aims of the work are development of method for compatibility of montmorillonite (MMT) with polyvinylpyrrolidone (PVP) in order to use the obtained mixture for the modification of polar and non-polar polymers and determination of modified montmorillonite effect on physico-mechanical, thermo-physical and insulating properties of polycaproamide PA-6.

\section{Experimental Section}

To obtain montmorillonite-polyvinylpyrrolidone mixture (MPM) we used polyvinylpyrrolidone with molecular weight of $12600 \pm 2700$ and "Fluka" montmorillonite supplied by Sigma-Aldrich firm. PVP and MMT solutions were prepared in water with corresponding concentrations to obtain the following

* Corresponding author: Krasinskyi Volodymyr, PhD., E-mail address: vkrasinsky82@gmail.com 
PVP:MMT ratios (w/w): $7: 1 ; 5: 1 ; 3: 1 ; 1: 1$ and 1:2. Before mixing with PVP the colloid solutions of MMT were pretreated by ultrasonic waves with the frequency of $22 \mathrm{kHz}$ for 3 min using apparatus "Volna UZTA$0.4 / 22-O M "$ ". Then PVP and MMT solutions were mixed using a mechanical stirrer and the obtained solution was treated by ultrasound for $15 \mathrm{~min}$. Ultrasonic waves set in motion a limited volume of treated solution and carry out the local effects with ultrasonic frequencies ensuring high rate and efficiency of mixing. Then mixtures were dried under vacuum at $80^{\circ} \mathrm{C}$ and obtained films were grinded in agate mortar till fine-dispersed powder was obtained.

While mixing MPM with PA-6 in the melt in plunger-capillary plasticator at $230^{\circ} \mathrm{C}$ and loading of $5 \mathrm{~kg}$ we obtained granulated concentrate based on PA-6 polyamide with MPM content corresponding to $7 \mathrm{wt} \%$ of montmorillonite. Then we mixed the concentrate with pure PA-6 and obtained composites with different content of MMT.

Plasticization of obtained composites was carried out using injection machine Kuasy 32/25 and samples were casted as standard blades. Injection moulding parameters are:

1) Temperatures of the zones of injection machine material cylinder-215, 230 and $245^{\circ} \mathrm{C}$;

2) Temperature of the mold $-18^{\circ} \mathrm{C}$;

3) Moulding pressure - $100 \mathrm{MPa}$;

4) Exposing time under pressure - $10 \mathrm{~s}$;

5) Exposing time for cooling $-15 \mathrm{~s}$.

\section{Results and Discussion}

There is a physical interaction between PVP and MMT macromolecules if their aqueous solutions are mixed in ultrasound field with the frequency of $22 \mathrm{kHz}$. Higher thermal stability of the obtained composites (compared with pure PVP), the results of X-ray and DTA analyses confirm the abovementioned fact $[4,5]$.

The developed MPM may be used as a modifier for polar and non-polar polymers. From the economic and technological points of view the composite with MMT:PVP $=1: 5$ is the most profitable one, therefore it is interesting to study its effect on the properties of thermoplastic polymers.

To demonstrate the effect of MPM on the structure and properties of nanocomposite based on it we selected the most used and popular commercial polymer - polyamide-6. The development of new layered-silicate nanocomposites based on polyamide- 6 should extend the areas of their application as the construction materials due to their improved physico-chemical characteristics and fire resistance.

Tension curves of the composite PA-6/MPM are represented in Fig. 1 depending on MPM content (relative to pure MMT). For PA-6 and composite with MPM content corresponding to $2.5 \mathrm{wt} \%$ of MMT we obtain the curves (curves 1, 2), for which the area of stimulated elasticity is typical. However for MPM even with small amount of MMT we observe smaller deformation but higher value of tension. Flowability limit for the composite containing $2.5 \mathrm{wt} \%$ of MMT (curve 2) is higher than that of PA-6 (curve 1). At the same time the elongation at tension of pure PA-6 is twice greater than the value of the composite containing $2.5 \mathrm{wt} \%$ of MMT.

Tension curves of the composite PA-6/MPM corresponding to MMT content of 5 and 7 wt $\%$ (curves 3 and 4, Fig. 1) have other nature compared with pure PA-6. The tension increases proportional to deformation and samples are destroyed at the stage of neck formation at small values of the elongation at break within the limits of $20 \%$.

The pure PA- 6 has the greatest value of elongation at tension and the smallest breaking strength (Fig. 1, Table 1). The increase of MPM content in the composite decreases the elongation and increases breaking force. For the sample with MMT content of $7 \mathrm{wt} \%$ it is higher by $17 \mathrm{MPa}$ than that of pure PA-6. At MMT content in the composite of more than $5 \mathrm{wt} \%$ the elongation at tension decreases threefold.

Young's modulus (elastic modulus of the first order) has the similar dependence on MMT content in the composite based on PA-6: with the increase of MMT content Young's modulus increases but more sharply than the increase of breaking force (Table 2). At MMT content of $2.5 \mathrm{wt} \%$ it is higher by $40 \%$ compared with pure PA-6, and at the content of $7 \mathrm{wt} \%$ it is higher by $60 \%$. The breaking force of the composite with MMT content of $7 \mathrm{wt} \%$ is higher by $45 \%$ than that of pure PA-6.

The introduction of MPM into PA- 6 increases tensile strength of the samples, as well as hardness and bending strength (Table 2). At MPM content corresponding to $2.5 \%$ of MMT in PA- 6 bending strength and elasticity modulus at bending are 
increased twice and at MMT content of 5-7\% bending strength increases by more than threefold (Table 2).

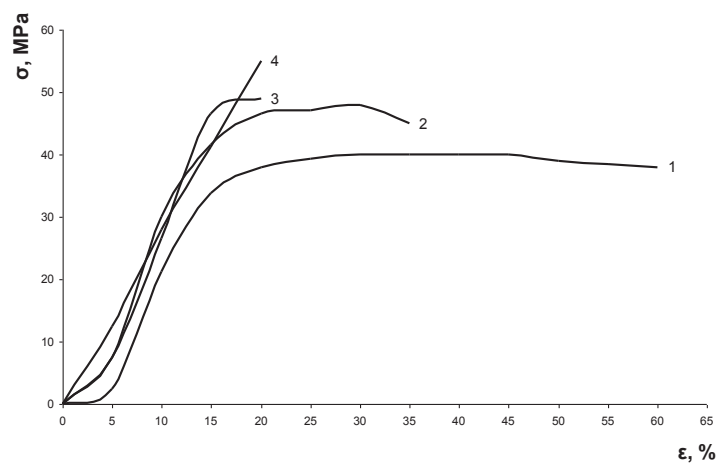

Fig. 1: Tension curves of the samples depending on MPM content $(M M T: P V P=1: 5): 1-P A-6 ; 2-(P A-6+2,5 \% M M T) ; 3-(P A-6+5 \%$ MMT); $4-(P A-6+7 \%$ MMT).

Table 1: Effect of MMT content in MPM* on physic-mechanical properties of PA-6 at tension.

\begin{tabular}{|c|c|c|c|c|}
\hline Sample & PA-6 & $\begin{array}{c}\text { PA-6 / 2.5\% } \\
\text { MMT }\end{array}$ & $\begin{array}{c}\text { PA-6 / 5.0\% } \\
\text { MMT }\end{array}$ & $\begin{array}{c}\text { PA-6 / 7.0\% } \\
\text { MMT }\end{array}$ \\
\hline$\sigma_{\text {break, }} \mathbf{M P a}$ & 38 & 45 & 49 & 55 \\
\hline $\boldsymbol{\sigma}_{\max , \mathbf{M P a}}$ & 40 & 48 & - & - \\
\hline $\boldsymbol{\varepsilon}, \%$ & 60 & 36 & 21 & 19 \\
\hline E, MPa & 1160 & 1602 & 1685 & 1810 \\
\hline
\end{tabular}

*MPM - MMT:PVP $=1: 5$

where Obreak - breaking strength, MPa;

$\sigma_{\max }-$ maximum tensile strength, $\mathrm{MPa}$;

$\varepsilon$ - elongation at break, \%;

$E$ - Young's modulus, MPa.

Table 2: Effect of MPM content on PA-6 physico-mechanical properties at bending.

\begin{tabular}{|c|c|c|c|c|}
\hline Sample & PA-6 & $\begin{array}{c}\text { PA-6 / 2.5\% } \\
\text { MMT }\end{array}$ & $\begin{array}{c}\text { PA-6/5.0\% } \\
\text { MMT }\end{array}$ & $\begin{array}{c}\text { PA-6 / } \\
\mathbf{7 . 0 \%} \text { MMT }\end{array}$ \\
\hline Parameter & 16,5 & 33,0 & 54,0 & 55,5 \\
\hline Obend, $_{\text {MPa }} \mathbf{M P a}$ & 1050 & 2020 & 2580 & 2600 \\
\hline $\mathbf{H B}, \mathbf{M P a}$ & 47,7 & 77,4 & 119,2 & 135,4 \\
\hline
\end{tabular}

*MPM - MMT:PVP = 1:5

where $\sigma_{b e n d}-$ bending strength at flexure of 10 $\mathrm{mm}, \mathrm{MPa}$;

$H B$ - Brinell hardness, MPa;

Ebend - elasticity modulus at bending, MPa.

Brinell hardness of the samples also depends on MPM content - the increase of MMT amount in the composite its hardness constantly increases. MMT content of $2.5 \mathrm{wt} \%$ increases the hardness by $60 \%$ and $7 \mathrm{wt} \%$ of MMT - by $180 \%$.

Improvement of PA-6 physico-mechanical properties while introducing MPM into it is a result of effective exfoliation of modified montmorillonite particles in polyamide, nanosilicate separation into layers, and likely formation of high-crystalline materials based on PA-6 and MMT.

Introducing MPM to PA-6 we improve the heat resistance and insulating properties of the obtained composites but the value of water absorption is constant (Table 3). The composite with MPM content corresponding to 2.5 wt\% of MMT has the best insulation properties. The increase in conductivity of the samples with MMT content of more than $2.5 \mathrm{wt} \%$ may be explained by the increase of hygroscopic MPM amount in the composite. The investigation results concerning water absorption of such composites confirm this fact. The increase in MPM content increases water absorption.

Table 3: Effect of MPM content on the operational properties of PA-6.

\begin{tabular}{|c|c|c|c|c|}
\hline Sample & PA-6 & $\begin{array}{c}\text { PA-6 / 2.5\% } \\
\text { MMT }\end{array}$ & $\begin{array}{c}\text { PA-6 / 5.0\% } \\
\text { MMT }\end{array}$ & $\begin{array}{c}\text { PA-6 / } \\
\mathbf{7 . 0 \%} \text { MMT }\end{array}$ \\
\hline $\mathbf{\rho}_{\mathbf{v}} \cdot \mathbf{1 0} \mathbf{1 0}^{-10}, \mathbf{O h m} \cdot \mathbf{m}$ & 1,4 & 17,4 & 12,6 & 10,0 \\
\hline $\mathbf{T}_{\mathbf{r}}{ }^{\circ} \mathrm{C}$ & 190 & 205 & 212 & 215 \\
\hline $\mathbf{T}_{\text {melt }}{ }^{\circ} \mathrm{C}$ & 205 & 220 & 224 & 228 \\
\hline Water sorption for 24 hrs, \% & 2,22 & 1,98 & 2,12 & 2,31 \\
\hline
\end{tabular}

*MPM - MMT:PVP $=1: 5$

where $\rho_{v}$ - specific volume electrical resistance, Ohm.m;

$T_{v}, T_{\text {melt }}$ - heat stability according to Vicat and melting point of the composites, ${ }^{\circ} \mathrm{C}$.

The introduction of MPM into PA- 6 also increases its heat stability according to Vicat and melting point. The increase of MMT content in the composites increases both values. At MMT content of 5-7wt\% heat stability according to Vicat and melting point of polyamide increase by more than $20^{\circ} \mathrm{C}$.

The experimental results represented in Table 3 additionally confirm the effect of developed nanomodifier - MPM - on the processing and operational properties of polyamide.

\section{Conclusions}

Thus, the experimental results confirm the positive effect of MPM in the composite with PA6, allow to determine the rational composition of nanomodifier for polymers based on montmorillonite modified by polyvinylpyrrolidone at PVP:MMT ratio of 5:1 and confirm its efficiency while obtaining composites on the basis of polyamide- 6 and MPM in the melt. The introduction 
of the developed MPM into polyamide in small amounts significantly improves its mechanical, thermophysical and insulating properties but reduces its elasticity. Therefore the developed composites based on PA-6 with filler may be recommended for the production of construction materials with increased hardness and strength.

\section{References and Notes}

[1] Wagener, R., Reisinger, T.J.G. (2003). Rheological method to compare the degree of exfoliation of nanocomposites. Polymer, 44, 7513-7518.

[2] Ślusarczyk, C., Biniaś, W., Fabia, J., Biniaś, D. (2007). DSC and Two-dimensional Correlation Infrared Spectroscopy Studies of PA6/Montmorillonite Composite Fibres. Fibres \& Textiles in Eastern Europe, 5-6 (64), 22-26.

[3] Suberlyak, O.V., Krasins'kyi, V.V., Moravs'kyi, V.S., Gerlach, H., Jachowicz T. (2014). Influence of Aluminosilicate Filler on the Physicomechanical Properties of PolypropylenePolycaproamide Composites. Materials Science, 50, 2, 296302.

[4] Krasinskyi, V., Suberlyak, O., Klym, Y., Gajdos, I. (2014). Innovative production of nanocomposites on the basis of thermoplastics and montmorillonite modified by polyvinylpirrolidone. XVII International Scientific Conference "Trends and Innovative Approaches in Business Processes", P. 1-6.

[5] Krasinskyi, V., Suberlyak, O., Klym, Y., Gajdos, I., Jachowicz, T. (2015). Nanocomposites on the basis of termoplastics and montmorillonite modified by polyvinylpyrrolidone. Editor Janusz Sikora, Technological and design aspects of extrusion and injection moulding of thermoplastic polymer composites and nanocomposites. Volume III: Lublin, P. 103112. 